\title{
Case Report \\ Importance of Continuous Pulse Oximetry of the Ipsilateral Thumb/Index Finger during Transradial Angiography
}

\author{
Ross C. Puffer ${ }^{1}$ and David F. Kallmes ${ }^{2}$ \\ ${ }^{1}$ Mayo Medical School, Mayo Clinic, Rochester, MN 55905, USA \\ ${ }^{2}$ Department of Radiology, Mayo Clinic, Rochester, MN 55905, USA \\ Correspondence should be addressed to David F. Kallmes, Kallmes.david@mayo.edu
}

Received 2 November 2011; Accepted 9 December 2011

Academic Editors: T. Ho and D. Lee

Copyright ( 2011 R. C. Puffer and D. F. Kallmes. This is an open access article distributed under the Creative Commons Attribution License, which permits unrestricted use, distribution, and reproduction in any medium, provided the original work is properly cited.

\begin{abstract}
We present a case of a 63-year-old male undergoing attempted basilar artery embolization using a right transradial artery approach in which continuous pulse oximetry of the ipsilateral thumb uncovered unanticipated hand ischemia during the procedure. A preprocedural evaluation using pulse oximetry of the right thumb demonstrated normal waveform and maintenance of normal oxygen saturation during manual compression of the right radial artery. This normal waveform and oxygen saturation was maintained after insertion of a $6 \mathrm{Fr}$ sheath into the radial artery. After insertion of a 6Fr guiding catheter into the right vertebral artery, near-complete dampening of the pulse oximetry waveform and precipitous decline in oxygen saturation were noted. Examination of the right hand demonstrated poor tissue perfusion. Immediate removal of the guiding catheter led to return of a normal waveform, oxygen saturation, and tissue perfusion. This case demonstrates the importance of continuous, intraprocedural monitoring of oxygenation of the ipsilateral hand during transradial angiography in order to avoid unanticipated perfusion abnormalities.
\end{abstract}

\section{Introduction}

One of the most serious complications of the transradial approach is radial artery occlusion secondary to lack of sufficient collateral flow through the ulnar artery and palmar arch [1-5]. This is also the most common complication, having an incidence of $2-18 \%$ depending on techniques used [2-5]. Numerous maneuvers have been proposed to assess risk for inadequate tissue perfusion with radial artery occlusion. The most well known of these maneuvers is the Allen test, but the subjective nature of this test limits its efficacy. Pulse oximetry of the ipsilateral thumb or index finger during manual compression of the radial artery has been shown to correlate with Doppler imaging in its ability to characterize ulnar collateral flow, making it a more accurate and superior evaluation tool as compared to the Allen test [6-8]. While pulse oximetry of the ipsilateral thumb or index finger is commonly used as a preprocedure evaluation technique, we have found continuous, intraprocedural pulse oximetry monitoring of the ipsilateral thumb or index finger useful to avoid ischemic complications. In order to illustrate this point, we offer a case report in which intraprocedural pulse oximetry identified unanticipated ischemia of the ipsilateral hand during transradial angiography.

\section{Case}

A 63-year-old man presented to our institution for endovascular treatment of a large, right vertebrobasilar aneurysm. Prior to radial artery catheterization, a pulse oximeter was placed on the right thumb and a stable waveform and oxygen saturation were obtained. During manual compression of both the right radial and ulnar artery, complete damping of waveform was noted. Upon release of the ulnar arterial compression, a robust waveform, identical to the baseline waveform, returned immediately, along with normal oxygen saturation. The pulse oximeter was left in place on the right thumb.

Using a transradial approach, a $6 \mathrm{Fr}$ sheath was placed, with maintenance of a normal waveform. A $6 \mathrm{Fr}$ guiding 
catheter (Envoy) was placed into the right vertebral artery. Several minutes later, the nurse anesthetist alerted the physician that the waveform had flattened substantially and that the oxygen saturation dropped precipitously. Examination of the right hand demonstrated poor capillary refill. The guiding catheter was removed and a normal waveform returned to the pulse oximeter, associated with normal oxygen saturation. The case was completed from a transfemoral approach. Following the basilar artery embolization from the femoral approach, the radial and femoral sheaths were removed. The right hand remained normal, without evidence for ischemic complications.

\section{Discussion}

We routinely apply continuous, intraprocedural pulse oximetry of the ipsilateral thumb or index finger, as opposed to preprocedure monitoring alone, to determine adequate perfusion of the hand during interventional procedures in which transradial access is attempted. The case that we present here demonstrates that even when preprocedure pulse oximetry confirms that flow through the ulnar artery is sufficient to perfuse the hand when the radial artery is completely occluded, various techniques and manipulations used during the procedure may induce hand ischemia. We presume that in our case, the guiding catheter impeded flow in an important collateral vessel and that prompt removal of the catheter thus restored adequate collateral flow. Without prompt identification and treatment of hand ischemia, thrombotic or ischemic complications might have occurred. Thus, we conclude that it is important to monitor the perfusion of the hand not only in the preprocedure setting but also throughout the duration of the intervention to ensure that the hand is not at risk for ischemic damage.

The transradial approach is being used more often in the setting of vascular intervention, and common complications attributable to this technique are becoming better understood. We are not aware of any previous studies demonstrating the importance of intraoperative pulse oximetry of the ipsilateral thumb or index finger to monitor perfusion of the hand, even though preprocedural pulse oximetry is routine in many institutions [9]. Further, numerous, previous studies have shown the serious effects of hand ischemia in the setting of radial artery occlusion without adequate collateral flow through the ulnar artery and palmar arch, highlighting the importance of tissue perfusion during and after transradial angiography $[1,3,5,10-16]$.

We realize that this finding was observed in a single patient and that we have not shown the incidence of this complication in a large series. Even so, we believe that intraoperative monitoring is an excellent method of early detection of hand ischemia and that through the use of this monitoring technique, further studies may uncover the true incidence of this complication.

\section{Conclusions}

Using pulse oximetry to monitor blood flow to the hand during a transradial angiographic procedure is an efficient method to prevent silent ischemia from occurring during the operation.

\section{Disclosure}

No part of this paper has been presented or previously published.

\section{References}

[1] Y. Kanei, T. Kwan, N. C. Nakra et al., "Transradial cardiac catheterization: a review of access site complications," Catheterization and Cardiovascular Interventions, vol. 78, no. 6, pp. 840-846, 2011.

[2] J. M. Cubero, J. Lombardo, C. Pedrosa et al., "Radial compression guided by mean artery pressure versus standard compression with a pneumatic device (RACOMAP)," Catheterization and Cardiovascular Interventions, vol. 73, no. 4, pp. 467-472, 2009.

[3] S. Pancholy, J. Coppola, T. Patel, and M. Roke-Thomas, "Prevention of radial artery occlusion-patent Hemostasis Evaluation Trial (PROPHET study): a randomized comparison of traditional versus patency documented hemostasis after transradial catheterization," Catheterization and Cardiovascular Interventions, vol. 72, no. 3, pp. 335-340, 2008.

[4] S. B. Pancholy, "Impact of two different hemostatic devices on radial artery outcomes after transradial catheterization," Journal of Invasive Cardiology, vol. 21, no. 3, pp. 101-104, 2009.

[5] M. Sanmartin, M. Gomez, J. R. Rumoroso et al., "Interruption of blood flow during compression and radial artery occlusion after transradial catheterization," Catheterization and Cardiovascular Interventions, vol. 70, no. 2, pp. 185-189, 2007.

[6] A. Sachithanandan, A. Ahmed, A. Muir, and A. Graham, "Simple method for monitoring hand perfusion following radial artery harvest for coronary artery bypass grafting," Interactive Cardiovascular and Thoracic Surgery, vol. 1, no. 1, pp. 50-51, 2002.

[7] N. A. Wisely and L. B. Cook, "Arterial flow waveforms from pulse oximetry compared with measured Doppler flow waveforms," Anaesthesia, vol. 56, no. 6, pp. 556-561, 2001.

[8] G. R. Barbeau, F. Arsenault, L. Dugas, S. Simard, and M. M. Larivière, "Evaluation of the ulnopalmar arterial arches with pulse oximetry and plethysmography: comparison with the Allen's test in 1010 patients," American Heart Journal, vol. 147, no. 3, pp. 489-493, 2004.

[9] O. F. Bertrand, S. V. Rao, S. Pancholy et al., "Transradial approach for coronary angiography and interventions: results of the first international Transradial practice survey," JACC: Cardiovascular Interventions, vol. 3, no. 10, pp. 1022-1031, 2010.

[10] R. J. Valentine, J. G. Modrall, and G. P. Clagett, "Hand ischemia after radial artery cannulation," Journal of the American College of Surgeons, vol. 201, no. 1, pp. 18-22, 2005.

[11] H. Benamer, T. Lefèvre, N. Salvatella, Y. Louvard, and S. Pande, "Fundamental issues to be addressed before and during a transradial procedure," Indian Heart Journal, vol. 62, no. 3, pp. 206-210, 2010.

[12] C. J. Cooper, R. A. El-Shiekh, D. J. Cohen et al., "Effect of transradial access on quality of life and cost of cardiac catheterization: a randomized comparison," American Heart Journal, vol. 138, no. 3, pp. 430-436, 1999.

[13] S. S. Jolly, S. Amlani, M. Hamon, S. Yusuf, and S. R. Mehta, "Radial versus femoral access for coronary angiography or 
intervention and the impact on major bleeding and ischemic events: a systematic review and meta-analysis of randomized trials," American Heart Journal, vol. 157, no. 1, pp. 132-140, 2009.

[14] S. Rathore and J. L. Morris, "The radial approach: is this the route to take?" Journal of Interventional Cardiology, vol. 21, no. 5, pp. 375-379, 2008.

[15] M. Sanmartin, J. Goicolea, R. Ocaranza, D. Cuevas, and F. Calvo, "Vasoreactivity of the radial artery after transradial catheterization," Journal of Invasive Cardiology, vol. 16, no. 11, pp. 635-638, 2004.

[16] P. R. Stella, F. Kiemeneij, G. J. Laarman, D. Odekerken, T. Slagboom, and R. van der Wieken, "Incidence and outcome of radial artery occlusion following transradial artery coronary angioplasty," Catheterization and Cardiovascular Diagnosis, vol. 40, no. 2, pp. 156-158, 1997. 


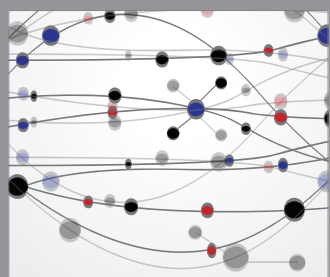

The Scientific World Journal
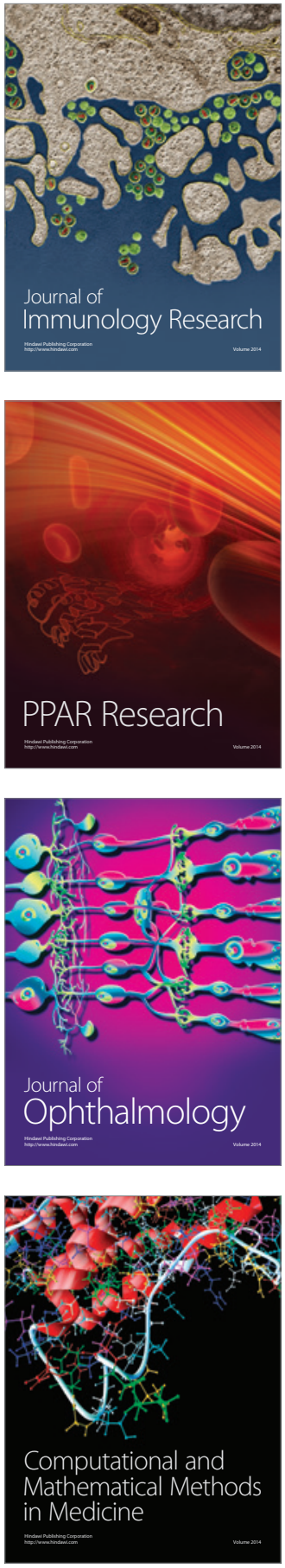

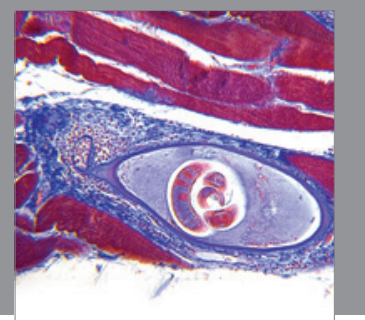

Gastroenterology

Research and Practice
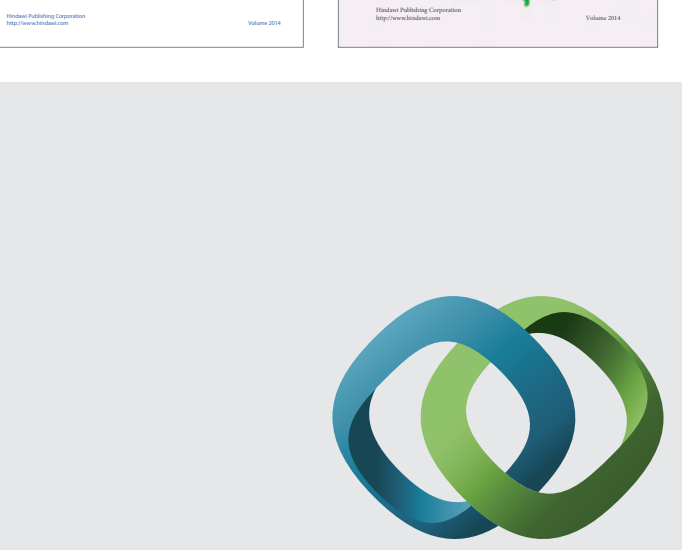

\section{Hindawi}

Submit your manuscripts at

http://www.hindawi.com
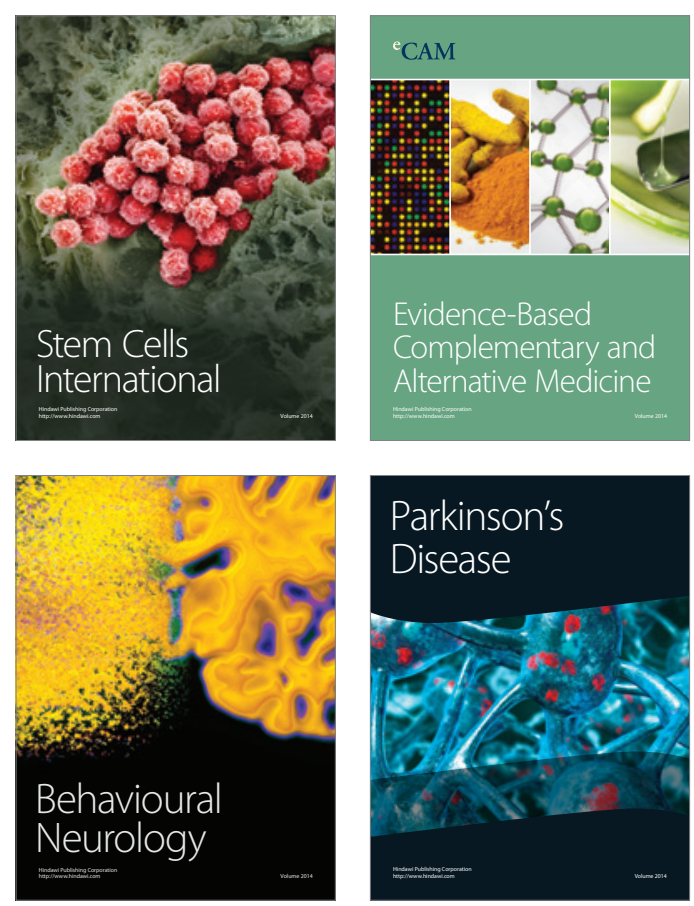

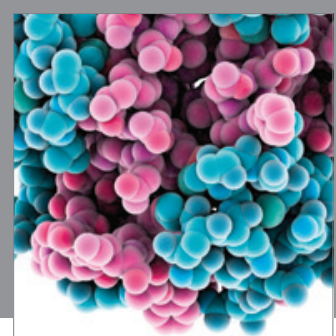

Journal of
Diabetes Research

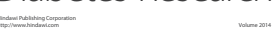

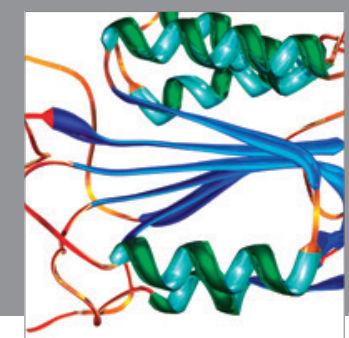

Disease Markers
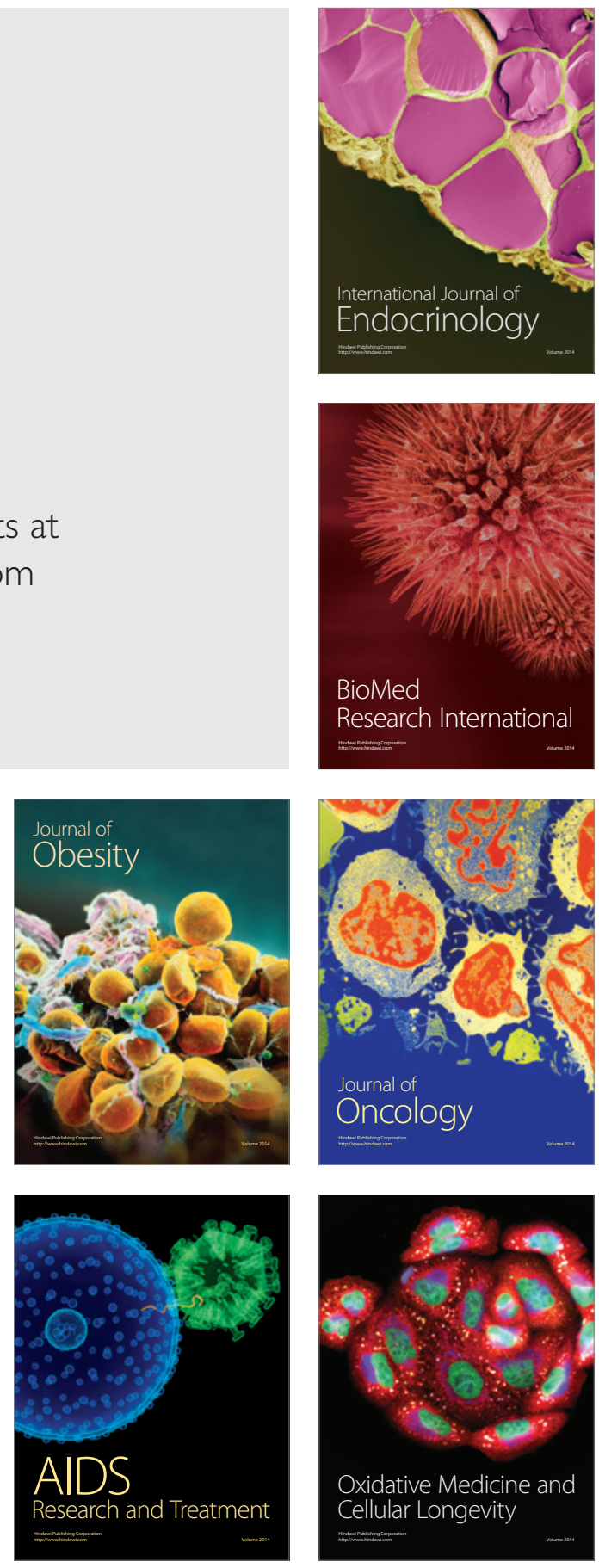